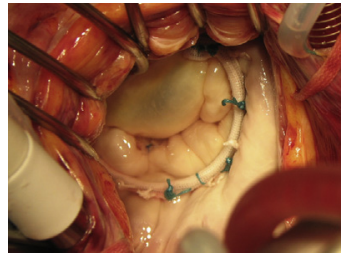

\section{LEFT VENTRICULAR FUNCTION AFTER MITRAL SURGERY: TIME TO FOCUS ON INTRAOPERATIVE MANAGEMENT?}

\section{To the Editor:}

We read with interest the article by Quintana and colleagues ${ }^{1}$ and a letter to the Editor by Buckberg and Athanasuleas $^{2}$ about this article published in the Journal in December 2014 and March 2015, respectively. We have some observations for the authors.

We focused our attention on Table 2, "Comparison of Postoperative Clinical Course Stratified by Early Predismissal LVEF," in the article by Quintana and colleagues. ${ }^{1}$ In the footnotes of the table, it is clear that the data are presented as median (interquartile range) or $\mathrm{n}(\%)$, but looking carefully at the line "Need for inotropic support," we found 2 mistakes: If 136 patients in the first group of 1391 (ejection fraction $[\mathrm{EF}] \geq 50$ ) required inotropic support, they do not represent $28 \%$ but $9.77 \%$. The same applies to the second group $(\mathrm{EF} \leq 50)$ of 50 patients of 314 . They do not represent $37.3 \%$ but $15.9 \%$. This error is reported in the results: "As expected, patients with early dysfunction required more frequently postoperative inotropic support ( $28 \%$ vs $37.3 \%, P=.04)$," but in the light of the wrong percentage calculation, the $P$ value may be incorrect.

The second observation is related to the need of intraaortic balloon pump (IABP). The authors report the same incidence of IABP use in the 2 groups. This event could be explained assuming that patients in the first group (EF $>50 \%$ ) have had a transitory left ventricular dysfunction (stunning) requiring IABP support, which quickly resolved without leaving any sign at predismissal echocardiographic evaluation. This hypothesis strongly strengthens the suspicion of an inadequate intraoperative protection in these groups of patients. ${ }^{2}$ Finally, the authors give no definition for "Need for inotropic support," especially regarding the duration ( $>6$ hours, $>12$ hours, $>24$ hours).

These data support the need to expand our research not only in the preoperative evaluation of patients with mitral

\footnotetext{
The Editor welcomes submissions for possible publication in the Letters to the Editor section that consist of commentary on an article published in the Journal or other relevant issues. Authors should: $\bullet$ Include no more than 500 words of text, three authors, and five references. • Type with double-spacing. • See http://jtcs.ctsnetjournals.org/ misc/ifora.shtml for detailed submission instructions. • Submit the letter electronically via jtcvs.editorialmanager.com. Letters commenting on an article published in the JTCVS will be considered if they are received within 6 weeks of the time the article was published. Authors of the article being commented on will be given an opportunity of offer a timely response ( 2 weeks) to the letter. Authors of letters will be notified that the letter has been received. Unpublished letters cannot be returned.
}

insufficiency but also in their intraoperative management with the objective to limit as much as possible the intraoperative damage related to cardiac arrest.

\section{Giuseppe Crescenzi, $M D^{a}$ Filippo Capestro, $M D^{b}$ Lucia Torracca, $M D^{b}$ \\ ${ }^{a}$ Division of Postoperative Intensive Care of Azienda Ospedaliero-Universitaria Ospedali Riuniti Ancona, Italy \\ ${ }^{b}$ Division of Cardiac Surgery of Azienda Ospedaliero- Universitaria Ospedali Riuniti Ancona, Italy}

\section{References}

1. Quintana E, Suri RM, Thalji NM, Daly RC, Dearani JA, Burkhart HM, et al. Left ventricular dysfunction after mitral valve repair-the fallacy of "normal" preoperative myocardial function. J Thorac Cardiovasc Surg. 2014;148:2752-60.

2. Buckberg GD, Athanasuleas CL. Left ventricular dysfunction after valve mitral repair: predetermined or caused? J Thorac Cardiovasc Surg. 2015;149:94.

\section{http://dx.doi.org/10.1016/j.jtcvs.2015.04.046}

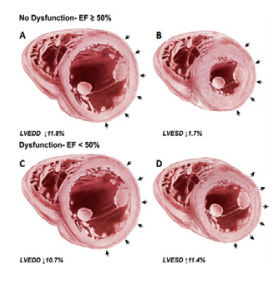

\section{CHANGES IN LEFT VENTRICULAR VOLUME AND DECLINE IN EJECTION FRACTION AFTER DEGENERATIVE MITRAL VALVE REPAIR: THE MATH MAKES SENSE}

\section{Reply to the Editor:}

We appreciate the interest shown in our work ${ }^{1}$ by the authors from Ancona. In regard to their first point, we confirm that the numbers presented in our article are correct. Documentation of the use of inotropic support was available in only 619 patients because of changes in recording methodology over time. Among these individuals, 433 received inotropic support and 186 did not. The presented percentages, $P$ values, and conclusions in the article are all accurate. Further, the frequency of intra-aortic balloon counterpulsation use was similar between groups with and without postoperative dysfunction, as documented.

The suggestion that a decrease in ejection fraction relates to the adequacy of myocardial protection reflects a commonly held misunderstanding regarding changes in ventricular volumes and left ventricular function immediately after correction of valvular regurgitation. ${ }^{2}$ Consider, for instance, a minimally symptomatic patient with an ejection fraction of $65 \%$ and severe mitral valve regurgitation. If one assumes that the regurgitant volume is $80 \mathrm{~mL}$ and that the patient has normal preoperative cardiac output with a forward stroke volume of $70 \mathrm{~mL}$, the preoperative left ventricular end-diastolic volume would necessarily be 
approximately $230 \mathrm{~mL}$. We know that end-diastolic volume changes little immediately after mitral valve repair. Thus, if Capestro and associates speculate that ideal myocardial protection should result in a "normal" ejection fraction, then a patient with severe mitral valve regurgitation undergoing repair would have a forward stroke volume of $150 \mathrm{~mL}$ after correction, producing an unphysiologic supranormal cardiac output $(>10 \mathrm{~L} / \mathrm{min})$, which of course, does not occur. The typical early physiologic adjustment to having a large end-diastolic volume after elimination of mitral regurgitation is a compensatory increase in end-systolic volume to maintain a normal or only slightly greater than normal stroke volume, translating into a decline in ejection fraction. In most patients, the decrease in ejection fraction early after correction of valvular regurgitation thus should be thought of as a compensatory mechanism and not a reflection of myocardial injury. This is discussed in detail in the clinical study by Ashikhmina and colleagues. ${ }^{3}$

Reverse remodeling of the ventricle subsequently occurs over time after successful correction of severe degenerative mitral regurgitation. As end-diastolic volume regresses, ejection fraction increases, but the extent of recovery is highly variable, often incomplete, ${ }^{4}$ and difficult to accurately predict. As documented in our article, persistent left ventricular dysfunction may occur even in patients who have a "normal" ejection fraction before mitral valve repair. To minimize the occurrence of this event and optimize outcomes of operation, valve repair should be undertaken before the development of excessive ventricular enlargement and pulmonary hypertension.

Rakesh M. Suri, MD, DPhil
Hartzell V. Schaff, MD
${ }^{a}$ Department of Thoracic and Cardiovascular Surgery
Cleveland Clinic
Cleveland, Ohio
Mivision of Thoracic and Cardiovascular Surgery
Mayo Clinic
Rochester, Minn

\section{References}

1. Quintana E, Suri RM, Thalji NM, Daly RC, Dearani JA, Burkhart HM, et al. Left ventricular dysfunction after mitral valve repair-the fallacy of "normal" preoperative myocardial function. J Thorac Cardiovasc Surg. 2014;148: 2752-62.

2. Buckberg GD, Athanasuleas CL. Left ventricular dysfunction after mitral valve repair: predetermined or caused? J Thorac Cardiovasc Surg. 2015; 149:940.

3. Ashikhmina EA, Schaff HV, Suri RM, Enriquez-Sarano M, Abel MD. Left ventricular remodeling early after correction of mitral regurgitation: maintenance of stroke volume with decreased systolic indexes. J Thorac Cardiovasc Surg. 2010;140:1300-5.

4. Suri RM, Schaff HV, Dearani JA, Sundt TM, Daly RC, Mullany CJ, et al. Determinants of early decline in ejection fraction after surgical correction of mitral regurgitation. J Thorac Cardiovasc Surg. 2008;136:442-7.

http://dx.doi.org/10.1016/j.jtcvs.2015.06.075

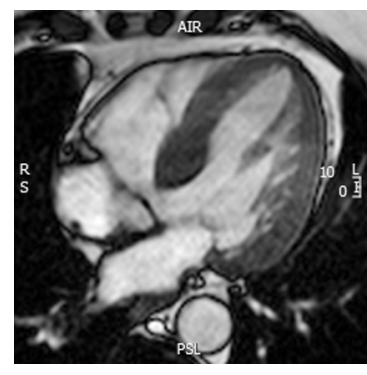

AORTIC VALVE REPLACEMENT AND THE RIGHT VENTRICLE-THE PLOT THICKENS

To the Editor:

We read with interest the recent article by Crouch and colleagues $^{1}$ describing the early effects of surgical and transcatheter aortic valve replacement on right ventricular (RV) function. The authors describe a fall in right ventricular ejection fraction (RVEF) assessed using cardiovascular magnetic resonance imaging - the gold standard technique for RV assessment - early following transcatheter aortic valve replacement (TAVR), but a relative preservation of RVEF following surgical aortic valve replacement (SAVR). We welcome the addition of further insight into RV reverse remodeling following TAVR and SAVR given the importance of RV function in prognosis following valve replacement.

The RV response to aortic valve replacement has not been well described and observations are limited to a small number of studies. In a similarly sized study published by our group, ${ }^{2}$ patients undergoing SAVR and TAVR had similar baseline RV size and ejection fraction. Our 6-month postprocedure cardiovascular magnetic resonance imaging study ${ }^{2}$ found that there was a trend toward an increase in RVEF in the TAVR group and a significant reduction in RVEF in the SAVR group. The cardiopulmonary bypass time and crossclamp times were longer in our study than that of Crouch and colleagues, ${ }^{1}$ which may have accounted for the different findings.

An echocardiography study by Kempny and colleagues supports the findings of our group. Those researchers studied 123 patients undergoing TAVR and SAVR and found a significant deterioration in longitudinal and radial RV function in those undergoing SAVR. There was no correlation between decline in RVEF and aortic crossclamp or cardiopulmonary bypass time. No deterioration of any parameter of RV function was seen following TAVR. Crouch and colleagues ${ }^{1}$ suggest that aortic regurgitation may be the mechanism for the deterioration in RVEF observed in the TAVR group. Although this is feasible, the postprocedure level of aortic regurgitation was still overall reduced compared with the preprocedure scan. Furthermore, the lack of an association in the study by Crouch and colleagues ${ }^{1}$ between left atrial size (a surrogate marker for elevated left atrial pressure) and RVEF seems to make this mechanism less plausible. The patients described in their article had 3 to 4 bouts of rapid pacing, which is greater than that performed at our institution. The hypotension associated with the rapid pacing may induce a global myocardial injury with a resultant impairment of RV function. Mechanisms that may be implicated in RV 